\title{
Red shift properties, crystal field theory and nephelauxetic effect on Mn4+-doped SrMgAl10-yGayO17 red phosphor for plant growth LED light
}

\section{Introduction}

China is an agricultural country, and plant cultivation plays an important role in agricultural production. Conventional agriculture suffers from harsh environment such as frost, cloudy, droughts and rainstorms, resulting in a reduced yield, which cannot satisfy people's needs. In recent years, indoor plant cultivation has caused a lot of concern for constructing a suitable and stable growing environment for plant growth. Light source is an essential condition in all process of plant growth including branching, flowering, and fruiting ${ }^{1-3}$. Light energy can be converted into chemical energy by photosynthesis of plant pigments. Chlorophyl A, chlorophyl B, phytochrome $\mathrm{P}_{\mathrm{R}}$ and phytochrome $\mathrm{P}_{\mathrm{FR}}$ are four main plan pigments which mainly absorb blue $(400-500 \mathrm{~nm})$, red $(600-700 \mathrm{~nm})$ and far-red $(700-750 \mathrm{~nm})$ lights. The traditional light source for indoor plant cultivation are mainly including incandescent lamps, high-pressure sodium lamps and fluorescent lamps, but they suffer from the disadvantages such as high energy consumption, short lifetime and spectral mismatch. Therefore, phosphor conversion light-emitting diode has gradually become the mainstream device in indoor plant culture for their saving of energy, long lifetime, spectral match and environment friendly. Phosphors play an indispensable role in LED devices which determines the photoluminescence propertied of the devices 
directly. Meanwhile, plant growth LEDs need to work for a long time under high power, therefore, it is important to design and synthesis the phosphors with proper spectral emission and excellent thermal stability ${ }^{4-6}$.

Based on this situation, many phosphors had been investigated and discussed to fulfil the light requirements of plant growth. The commercial phosphor $\mathrm{Y}_{3} \mathrm{Al}_{5} \mathrm{O}_{12}: \mathrm{Ce}^{3+}$ is widespread using in white LEDs, but it is not suitable for plant growth LEDs because mismatched spectral bands. As we all know, red and far-red lights have beneficial in promoting plant growth and biomass accumulation. Most of the researches on plant growth lighting focus on the red and blue emitting materials, but the far-red emission phosphor have little reported while far-red band is also a crucial part. Nowadays, the main commercial red phosphor are $\mathrm{Eu}^{2+}$-doped nitrides likes $(\mathrm{Ca}, \mathrm{Sr}) \mathrm{AlSiN}_{3}: \mathrm{Eu}^{2+}{ }^{7-9}$ and $\left(\mathrm{Ca}, \mathrm{Sr}_{2}\right)_{2} \mathrm{Si}_{5} \mathrm{~N}_{8}: \mathrm{Eu}^{2+}{ }^{20},{ }^{11}$. However, the preparation conditions for these phosphors are harsh, they usually need high temperature $\left(>1800^{\circ} \mathrm{C}\right)$ and high pressure in oxygen-free environment. The critical preparation requirement increases the cost of the product and limits their large-scale use in agricultural industry. Another red phosphor is $\mathrm{Mn}^{4+}$-doped fluoride, such as $\mathrm{K}_{2} \mathrm{TiF}_{6}: \mathrm{Mn}^{4+12}$ and $\mathrm{K}_{2} \mathrm{SiF}_{6}: \mathrm{Mn}^{4+}{ }^{13}$. The preparation of such materials is commonly used HF which is harmful to environment, and the product is unstable and easily decomposed in moist environment due to the existence of $\left[\mathrm{MnF}_{6}\right]^{2-}$ clusters. As an alternative, $\mathrm{Mn}^{4+}$-doped oxides have received extensive attention from researchers, for series advantages of them such as attractive photoluminescence properties, high stability, low cost and eco-friendliness ${ }^{14}$. Many $\mathrm{Mn}^{4+}$-doped oxides red emission 
phosphors have been investigated and reported. Zhou et al. ${ }^{15}$ summarized and described the characteristic emission lines of $\mathrm{Mn}^{4+}$ about $\mathrm{Mn}^{4+}$-activated luminescent materials systematically. The excitation wavelength of Mn-activated phosphors locates in the n-UV and blue region of $200-500 \mathrm{~nm}$, and could be efficiently excited by commercialized n-UV and blue chips. Most importantly, due to the characteristic transitions of ${ }^{2} \mathrm{E}_{\mathrm{g}} \rightarrow{ }^{4} \mathrm{~A}_{2}$, the emission band of these phosphors is located at red and far-red regions, matching well with the absorption of plant pigments. Other $\mathrm{Mn}^{4+}$-doped oxides such as $\mathrm{SrLaAlO}_{4}{ }^{16}, \mathrm{La}_{2} \mathrm{LiSbO}_{6}{ }^{17}, \mathrm{Gd}_{2} \mathrm{ZnTiO}_{6}{ }^{18}$ has also been reported for plan cultivation with characteristic red emission of $\mathrm{Mn}^{4+}$. Nonetheless, they still have many shortcomings such as low quantum efficiency, poor thermal stability and lack far-red band emission. Meanwhile, $\mathrm{Mn}^{4+}$-doped $\mathrm{Ca}_{14}(\mathrm{Ga} / \mathrm{Al})_{10} \mathrm{Zn}_{6} \mathrm{O}_{35}{ }^{19}, 20$ red phosphors were widely investigated by many researchers for their bright red emission, high quantum yield and good thermal stability.

Solid solution effect plays a key role on the design and preparation in $\mathrm{Mn}^{4+}$-doped $\mathrm{Ca}_{14}(\mathrm{Ga} / \mathrm{Al})_{10} \mathrm{Zn}_{6} \mathrm{O}_{35}$ phosphors. There are three conditions on solid solution effect can be described as similar ion radius, analogical structure and electronegativity alike. Zhao et al. ${ }^{21}$ and Zhou et al. ${ }^{22}$ reported the lattice site can be adjust by replacing $\mathrm{Ga}^{3+}$ with $\mathrm{Al}^{3+}$ in $\mathrm{Ca}_{14} \mathrm{Ga}_{10-\mathrm{x}} \mathrm{Al}_{\mathrm{x}} \mathrm{Zn}_{6} \mathrm{O}_{35}$ phosphor, for the lattice position of $\mathrm{Ga}^{3+}$ or $\mathrm{Al}^{3+}$ can be substituted by the activator, leading enhanced photoluminescence intensity and quantum efficiencies of samples. Analogously, Qiao et al. ${ }^{23}$ reported a single-phased white emission $\left(\mathrm{Ca}_{9-\mathrm{x}} \mathrm{Sr}_{\mathrm{x}}\right) \mathrm{MgK}\left(\mathrm{PO}_{4}\right)_{7}: \mathrm{Eu}^{2+}$ phosphor 
though tuning of the compositions and multiple activator sites, and the thermal stability increased significantly via $\mathrm{Sr}^{2+}$ to replace $\mathrm{Ca}^{2+}$. Similar improved quantum efficiency and thermal stability results were also seen in the in blue-emitting $\mathrm{Ba}_{2-\mathrm{x}} \mathrm{Sr}_{\mathrm{x}} \mathrm{SiO}_{4}: \mathrm{Ce}^{3+}$ phosphor ${ }^{24}$. Take inspiration from these literatures, we assumed $\mathrm{Ga}^{3+}$ to replace $\mathrm{Al}^{3+}$ in $\mathrm{SrMgAl}_{10} \mathrm{O}_{17}: \mathrm{Mn}^{4+}$ phosphor in order to enhance its luminescence properties. As far as we knows, there is no similar literature has been reported.

In this study, a novel $\mathrm{Mn}^{4+}$-doped $\mathrm{SrMgAl}_{10-\mathrm{y}} \mathrm{Ga}_{\mathrm{y}} \mathrm{O}_{17}$ red phosphor with tunable emission properties and great improved intensity are discovered, which synthesized via high-temperature solid-state method in atmospheric environment. The phase structure, photoluminescence (PL) and photoluminescence excitation (PLE) spectra, absorption spectra, quantum yield, lifetime decay curves and electroluminescence were investigated in details. Final, the LED device combined with blue chip and the as-obtained phosphors show bright blue and red emission which match with the plant absorption spectrum well, indicates this phosphor can be a candidate for indoor plant growth light.

\section{Experimental section}

The raw materials were $\mathrm{SrCO}_{3}(99.99 \%), \mathrm{MgO}(99.99 \%), \mathrm{Al}_{2} \mathrm{O}_{3}(99.99 \%), \mathrm{Ga}_{2} \mathrm{O}_{3}$ (99.99\%) and $\mathrm{MnCO}_{3}$ (99.99\%) which bought from Aladdin without further purification, in which different contents of $\mathrm{H}_{3} \mathrm{BO}_{3}(\mathrm{AR})(1 \% \mathrm{wt}, 2 \% \mathrm{wt}, 3 \% \mathrm{wt}, 4 \%$ $\mathrm{wt}, 5 \% \mathrm{wt}$ ) acted as flux in the reaction process to get the ideal samples without impurities. All reagents were weighed according to the stoichiometric ratio, put into 
an agate mortar and dropped with a certain amount of absolute ethyl alcohol to mix the materials up uniformly. These powders were ground for 30 minutes, and then transferred into corundum crucibles. They were put into a tube furnace preheated at $800{ }^{\circ} \mathrm{C}$ for 2 hours and sintered at $1500{ }^{\circ} \mathrm{C}$ in ambient atmosphere for 5 hours with a heating rate of $5{ }^{\circ} \mathrm{C} / \mathrm{min}$ in the whole process. The tube furnace was turned off to have the samples cool down to room temperature naturally. Finally the $\operatorname{SrMgAl}_{10} \mathrm{O}_{17}: \mathrm{xMn}^{4+}$ $(\mathrm{x}=0.1 \%, 0.3 \%, 0.5 \%, 1.0 \%, 1.5 \%, 2.0 \%)$ and $\operatorname{SrMgAl}_{10-\mathrm{y}} \mathrm{Ga}_{\mathrm{y}} \mathrm{O}_{17}: \mathrm{Mn}^{4+}(\mathrm{y}=1,2,3,4$, 5, 6) samples were obtained then reground to fine powders for further characterizations.

The X-ray powder diffraction (XRD) patterns were measured range from $20^{\circ}$ to $90^{\circ}$ by a diffractometer (D/SHIMADZU-6000, Japan) which equipped with $\mathrm{Cu}-\mathrm{Ka}$ radiation ( $\lambda=1.5406 \AA$ ). The scanning rate is $6 \%$ min and operating voltage and current are $40 \mathrm{kV}$ and $40 \mathrm{~mA}$. F-4700 fluorescence spectrophotometer (Hitachi, Japan) equipped with a $150 \mathrm{~W}$ Xe lamp was used to obtain the photoluminescence excitation (PLE) and photoluminescence (PL) spectra. The UV-vis absorption spectra were tested on U-3310 spectrophotometer (Hitachi, Japan). Temperature-dependent PL spectra were measured using F-7000 Spectro-photometer (Hitachi, Japan) by changing the testing temperature from $298 \mathrm{~K}$ to $473 \mathrm{~K}$. FLS 1000 fluorescence spectrometer (Edinburgh, UK) was used to get the lifetime curves and quantum efficiency.

\section{Results and discussion}

First of all, $\mathrm{H}_{3} \mathrm{BO}_{3}$ was chosen to as flux in the synthesis process, as shown in 
Fig.S1 (a), the XRD pattern of samples exhibit impurity phase of $\mathrm{SrAl}_{2} \mathrm{O}_{4}$ before the content of $\mathrm{H}_{3} \mathrm{BO}_{3}$ below 2 wt $\%$, after that the XRD represent pure phase of $\mathrm{SrMgAl}_{10} \mathrm{O}_{17}$ with the standard card of PDF\#26-0879. Considering the photoluminescence excitation (PLE) and photoluminescence (PL) spectra of samples with different content of flux, the emission intensity reached the maximum when 2 wt $\% \mathrm{H}_{3} \mathrm{BO}_{3}$ participates in the synthesis reaction, thus this condition was selected in the following section.

\subsection{Structure and phase characterization}
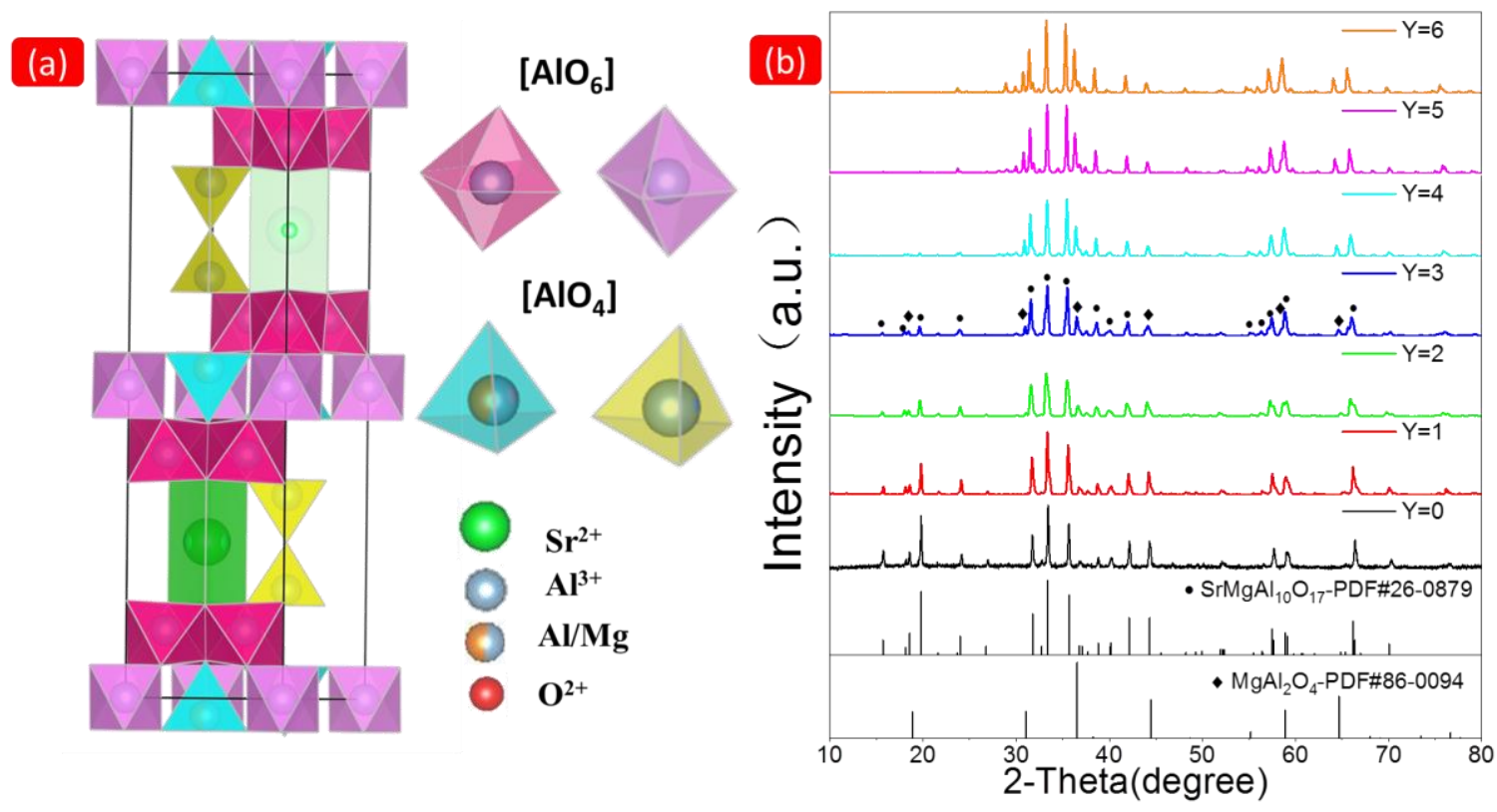

Fig. 1 (a) The crystal structure of $\mathrm{SrMgAl}_{10} \mathrm{O}_{17}$ host, the coordination environment of the octahedron $\left[\mathrm{AlO}_{6}\right]$ and tetrahedron $\left[\mathrm{AlO}_{4}\right]$; (b) The XRD patterns of $\mathrm{SrMgAl}_{10-\mathrm{y}} \mathrm{Ga}_{\mathrm{y}} \mathrm{O}_{17}: \mathrm{Mn}^{4+}(\mathrm{y}=0,1,2,3,4,5,6)$ phosphors.

The $\mathrm{SrMgAl}_{10} \mathrm{O}_{17}$ crystal belongs to $P 6_{3} / m m c$ space group with hexagonal structure as shown in Fig.1 (a). It's worth noting that asymmetric part of the unit cell contains four independent sites of $\mathrm{Al}^{3+}$ which be written as two $\left[\mathrm{AlO}_{6}\right]$ and two $\left[\mathrm{AlO}_{4}\right]$. One of them in tetrahedron $\left[\mathrm{AlO}_{4}\right]$ shares the position with $\mathrm{Mg}^{2+}$ randomly. In 
generally, activator ion $\mathrm{Mn}^{4+}$ prefer to replace $\mathrm{Al}^{3+}$ in octahedron $\left[\mathrm{AlO}_{6}\right]$ position for similar ionic radius of $\mathrm{Mn}^{4+}(r=0.530 \AA, \mathrm{CN}=6)$ and $\mathrm{Al}^{3+}(r=0.535 \AA, \mathrm{CN}=6)$, and different position substitution result in different emission spectrum for diverse crystal field. When a small quantity of $\mathrm{Mn}^{4+}$ replaced $\mathrm{Al}^{3+}$ in the $\mathrm{SrMgAl}_{10} \mathrm{O}_{17}$ matrix, the XRD patterns keep the original position without any shift, the experimental results are shown in $\quad$ (Dear Zhi Zhou, actually the shift of XRD pattern has no meaning. This is because the shift depends on both cell parameters and zero shift of the sample in the sample holder. I mean that even one powder can show absolutely different shifts of peaks! You need just pack the sample slightly differently. So we never should rely on pattern shift like many other persons make. The best way is to refine cell parameters during Rietveld refinement and plot cell volume per concentration - namely this is very precise information. By the way the sample shift from the zero surface is also refined parameter and adjusted during Rietveld refinement. In current manuscript we can: 1) leave current sentence and figure, if we will have a problem we know how to improve it; 2) I can make quickly Rietveld refinement and plot $\mathrm{V}(\mathrm{x})$ ) With $\mathrm{Ga}^{3+}$ doping into the phosphor, the $\mathrm{XRD}$ curves exhibited that samples change to complex phase gradually, as seen in Fig.1 (b). The sample match well with the standard card of $\mathrm{SrMgAl}_{10} \mathrm{O}_{17}$ at first, then $\mathrm{MgAl}_{2} \mathrm{O}_{4}$ with standard card of PDF\#86-0094 appeared and its content gradually increased. Concentrated on the sample when the doping content of $\mathrm{Ga}^{3+}$ is $\mathrm{y}=3$, its XRD pattern mainly consisted of $\mathrm{SrMgAl}_{10} \mathrm{O}_{17}$ and $\mathrm{MgAl}_{2} \mathrm{O}_{4}$, which noted as $\bullet$ and respectively. With the further increase of $\mathrm{Ga}^{3+}$ dopant, the phase of samples are 
mainly composed of $\mathrm{SrMgAl}_{10} \mathrm{O}_{17}$ host, $\mathrm{XAl}_{2} \mathrm{O}_{4}\left(\mathrm{X}=\mathrm{Mg}^{2+}, \mathrm{Mn}^{2+}\right)$ and $\mathrm{Ga}_{2} \mathrm{O}_{3}$, what should be notice is that the latter three compound have similar XRD pattern with almost the same peak position.

\subsection{Photoluminescence properties of $\mathrm{SrMgAl}_{10-\mathrm{y}} \mathrm{Ga}_{\mathrm{y}} \mathrm{O}_{4}: \mathrm{XMn}^{4+}$ phosphors}
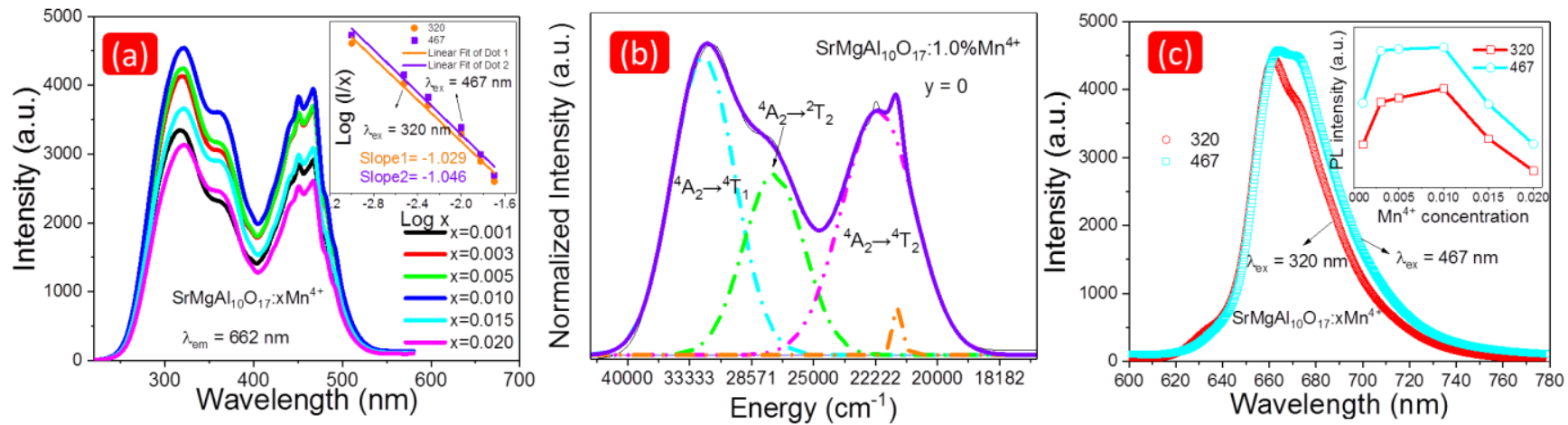

Fig. 2 (a) The photoluminescence excitation (PLE) spectra of $\operatorname{SrMgAl}_{10} \mathrm{O}_{17}: \mathrm{XMn}^{4+}$ $(\mathrm{x}=0.1 \%, 0.3 \%, 0.5 \%, 1.0 \%, 1.5 \%, 2.0 \%)$, inset is the dependence of $\log (I / x)$ versus $\log (x)$; (b) Gaussian fitting of $\mathrm{SrMgAl}_{10} \mathrm{O}_{17}: 1.0 \% \mathrm{Mn}^{4+}$ sample; (c) The photoluminescence (PL) spectra of samples under the excitation of $320 \mathrm{~nm}$ and 467 $\mathrm{nm}$ respectively, inset is the tendency of emission intensity varies with $\mathrm{Mn}^{4+}$ doping concentration.

Fig.2 (a) and (c) exhibit the PLE $\left(\lambda_{\mathrm{em}}=661 \mathrm{~nm}\right)$ and PL $\left(\lambda_{\mathrm{ex}}=320 \mathrm{~nm}\right.$ and $\lambda_{\mathrm{em}}$ $=467 \mathrm{~nm}$ ) spectra of $\mathrm{SrMgAl}_{10} \mathrm{O}_{17}: \mathrm{xMn}^{4+}$ phosphors. It is obvious that the intensity of excitation and emission increased with the rising concentration of $\mathrm{Mn}^{4+}$ at first, both of them reached maximum when $\mathrm{x}=1.0 \%$ then decreased with further more $\mathrm{Mn}^{4+}$ doping. In order to investigate the concentration quenching behavior of $\mathrm{SrMgAl}_{10} \mathrm{O}_{17}: \mathrm{xMn}^{4+}$ phosphor, the critical distance $R_{c}$ needs to take into account, the value of $R_{c}$ can be calculated by the following formula ${ }^{25,26}$ :

$$
R_{c} \approx 2\left[\frac{3 V}{4 \pi x_{c} N}\right]^{1 / 3}
$$

Where $V, x_{c}$ and $N$ stand for the volume of unit cell, the critical concentration of $\mathrm{Mn}^{4+}$ 
and the number of lattice sites can be occupied by $\mathrm{Mn}^{4+}$, respectively. For $\mathrm{SrMgAl}_{10} \mathrm{O}_{17}: \mathrm{xMn}^{4+}$ phosphor, the three values $V=616.8 \AA, x_{c}=0.010$ and $N=2$, accordingly the $R_{c}$ is estimated to be $38.91 \AA$. This value is much larger than $5 \AA$ which corresponding to the interaction between activator ions, therefore, the concentration quenching of $\mathrm{SrMgAl}_{10} \mathrm{O}_{17}: \mathrm{xMn}^{4+}$ belongs to the multipolar-multipolar interaction.

The multipolar-multipolar interactions usually involve three types named dipoledipole $(\mathrm{d}-\mathrm{d})$, dipole-quadrupole $(\mathrm{d}-\mathrm{q})$, and quadrupole-quadrupole $(\mathrm{q}-\mathrm{q})$ interactions, respectively. They refer to different value of $\theta$ in the following formula, which often used to reflect the interactions based on the Dexter's theory ${ }^{27,28}$ :

$$
\frac{I}{x}=k\left[1+\beta(\mathrm{x})^{\theta / 3}\right]^{-1}
$$

Where $I$ and $x$ mean the emission intensity and concentration of $\mathrm{Mn}^{4+}$ dopant, $k$ and $\beta$ are the same excitation condition and specific host crystal, and $\theta=6,8,10$ refer to d$\mathrm{d}, \mathrm{d}-\mathrm{q}$, and $\mathrm{q}-\mathrm{q}$ interactions, respectively.

The specific value of $\theta$ usually obtained by the slope of the dependence of $\log (I / x)$ versus $\log (x)$. From the inset of Fig.2 (a), the two fitting lines correspond to $320 \mathrm{~nm}$ and $467 \mathrm{~nm}$ wavelength excitation, two slopes are -1.029 and -1.046 , respectively. The $\theta_{1}$ and $\theta_{2}$ calculated to be 3.087 and 3.138 , both of them are close to 6 and indicated the concentration quenching mechanism of $\operatorname{SrMgAl}_{10} \mathrm{O}_{17}: \mathrm{xMn}^{4+}$ phosphor is dipole-dipole (d-d) interaction.

The photoluminescence spectra of $\operatorname{SrMgAl}_{10} \mathrm{O}_{17}: 1.0 \% \mathrm{Mn}^{4+}$ under $320 \mathrm{~nm}$ and $467 \mathrm{~nm}$ excitation in Fig.2 (c) show different forms that indicates two luminescence 
centers. For investigating the change of excitation peaks, Gaussian fitting was done for the spectrum of $\operatorname{SrMgAl}_{10} \mathrm{O}_{17}: 1.0 \% \mathrm{Mn}^{4+}$ sample. According to Fig.2 (b), this PLE spectrum was fitted into four Gaussian peaks located at 32154, 27247, 22123 and $21413 \mathrm{~cm}^{-1}$, they are related to ${ }^{4} \mathrm{~A}_{2} \rightarrow{ }^{4} \mathrm{~T}_{1},{ }^{4} \mathrm{~A}_{2} \rightarrow{ }^{2} \mathrm{~T}_{2}$ and ${ }^{4} \mathrm{~A}_{2} \rightarrow{ }^{4} \mathrm{~T}_{2}$ transitions of $\mathrm{Mn}^{4+}$, respectively.
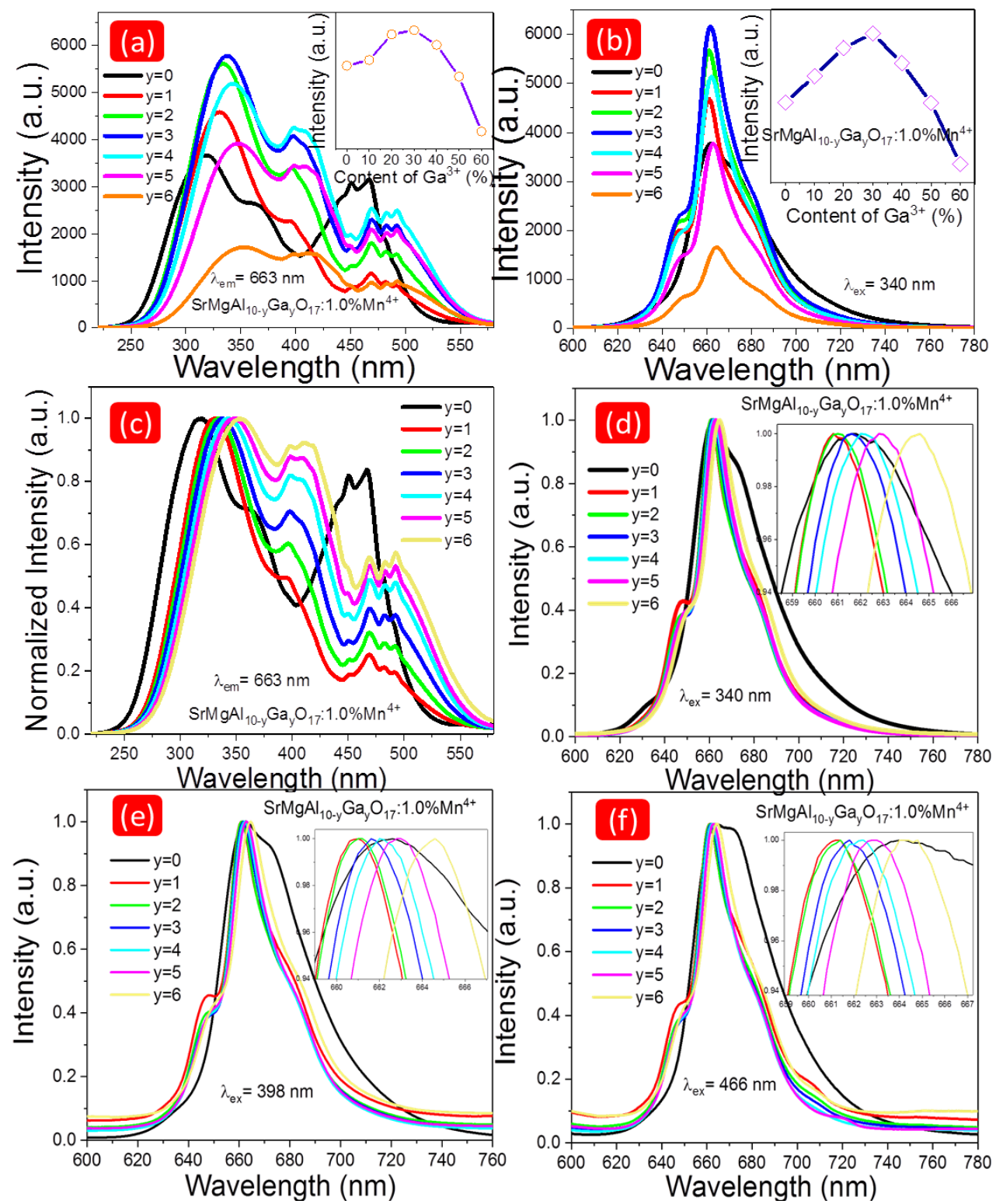

Fig.3 The (a) photoluminescence excitation and (b) photoluminescence spectra of $\mathrm{SrMgAl}_{10-\mathrm{y}} \mathrm{Ga}_{\mathrm{y}} \mathrm{O}_{17}: 1.0 \% \mathrm{Mn}^{4+}(\mathrm{y}=0,1,2,3,4,5,6)$ phosphors; the normalized PLE spectra (c) monitored at $663 \mathrm{~nm}$; the normalized PL spectra under (d) $340 \mathrm{~nm}$, (e) 398 $\mathrm{nm}$ and (f) $466 \mathrm{~nm}$ excitation, insets are enlarged part of the peaks. 
Series of $\mathrm{SrMgAl}_{10-\mathrm{y}} \mathrm{Ga}_{\mathrm{y}} \mathrm{O}_{17}: 1.0 \% \mathrm{Mn}^{4+}$ samples were obtained by selected the optimal doping concentration of $\mathrm{Mn}^{4+}$ at $1.0 \%$, and their photoluminescence excitation and photoluminescence spectra are shown in Fig.3. The intensity of PLE and PL spectra both increasing with an incremental content of $\mathrm{Ga}^{3+}$ doping, they reach to the maximum when $y=3$, after that show the trend of decrease with further more $\mathrm{Ga}^{3+}$ dopant. There is an interesting phenomenon, the normalized PLE spectra exhibit obvious red shift on each spectrum as shown in Fig.3 (c), for the ${ }^{4} \mathrm{~A}_{2} \rightarrow{ }^{2} \mathrm{~T}_{2}$ transitions show a great enhancement and red shift with the increase of $\mathrm{Ga}^{3+}$ doping. What's more, all PL spectra excited at different wavelength show slight red shift when the content of $\mathrm{Ga}^{3+}$ increasing.

Based on this situation, the change of crystal field is used to explain these phenomena. Crystal field parameters $D q$, the Racah parameters $B$ and $C$ are three indexes to assess the effect of crystal field strength on the luminescent properties of $\mathrm{Mn}^{4+}$, the value of these parameters are calculated by the PLE and PL spectra. The $D q$, $B$ and $C$ can be evaluated by the following equations ${ }^{29,30}$ :

$$
\begin{gathered}
D_{q}=\frac{E\left({ }^{4} T_{2}-{ }^{4} A_{2}\right)}{10} \\
\frac{D_{q}}{B}=\frac{15(x-8)}{\left(x^{2}-10 x\right)} \\
x=\frac{E\left({ }^{4} A_{2}-{ }^{4} T_{1}\right)-E\left({ }^{4} A_{2}-{ }^{4} T_{2}\right)}{D_{q}} \\
\frac{E\left({ }^{2} E_{g}-{ }^{4} A_{2}\right)}{B}=\frac{3.05 C}{B}+7.9-\frac{1.8 B}{D_{q}}
\end{gathered}
$$

According to Fig.2 (b), the energy of level of ${ }^{4} \mathrm{~T}_{1},{ }^{4} \mathrm{~T}_{2}$ and ${ }^{2} \mathrm{E}_{\mathrm{g}}$ in $\mathrm{SrMgAl}_{10} \mathrm{O}_{17}: 1.0 \% \mathrm{Mn}^{4+}$ are 32154, 22123 and $15082 \mathrm{~cm}^{-1}$, its $D q, B$ and $C$ are 
calculated to be 2212,1053 and $2561 \mathrm{~cm}^{-1}$, and the value of $D q / B$ is 2.1 , indicating that $\mathrm{Mn}^{4+}$ was exposed in a weak crystal field in $\mathrm{SrMgAl}_{10} \mathrm{O}_{17}$ matrix. However, the values of $D q / B$ are determined to be $2.22,2.23,2.24,2.35,2.43$ and 2.49 with the $\mathrm{Ga}^{3+}$ dopant increasing from $10 \%$ to $60 \%$ which mean stronger crystal field ${ }^{31}$, and this is the main reason for the red shift in luminescence spectra. The details of crystal field parameters and the energies states of $\mathrm{SrMgAl}_{10-\mathrm{y}} \mathrm{Ga}_{\mathrm{y}} \mathrm{O}_{17}: 1.0 \% \mathrm{Mn}^{4+}$ phosphors are shown in Table 1.

Table 1 Crystal Field Parameters and Energy States in $\operatorname{SrMgAl}_{10-\mathrm{y}} \mathrm{Ga}_{\mathrm{y}} \mathrm{O}_{17}: 1.0 \% \mathrm{Mn}^{4+}$ phosphors

\begin{tabular}{cccccccc}
\hline Sample & $\mathrm{D}_{\mathrm{q}} / \mathrm{B}$ & $\mathrm{D}_{\mathrm{q}}$ & $\mathrm{B}$ & $\mathrm{C}$ & $\begin{array}{c}{ }^{4} \mathrm{~A}_{2} \rightarrow \mathrm{T}_{1} \\
\left(\mathrm{~cm}^{-1}\right)\end{array}$ & $\begin{array}{c}{ }^{4} \mathrm{~A}_{2} \rightarrow{ }^{4} \mathrm{~T}_{2} \\
\left(\mathrm{~cm}^{-1}\right)\end{array}$ & $\begin{array}{c}{ }^{2} \mathrm{E} \rightarrow{ }^{4} \mathrm{~A}_{2} \\
\left(\mathrm{~cm}^{-1}\right)\end{array}$ \\
\hline $\mathrm{y}=0$ & 2.10 & 2212 & 1055 & 2561 & 32154 & 22124 & 15110 \\
$\mathrm{y}=1$ & 2.22 & 2110 & 951 & 2797 & 30303 & 21097 & 15133 \\
$\mathrm{y}=2$ & 2.23 & 2088 & 935 & 2833 & 29940 & 20877 & 15129 \\
$\mathrm{y}=3$ & 2.24 & 2070 & 924 & 2852 & 29674 & 20704 & 15115 \\
$\mathrm{y}=4$ & 2.35 & 2062 & 876 & 2952 & 29240 & 20619 & 15106 \\
$\mathrm{y}=5$ & 2.43 & 2058 & 847 & 3008 & 28986 & 20576 & 15088 \\
$\mathrm{y}=6$ & 2.49 & 2045 & 821 & 3051 & 28653 & 20450 & 15047 \\
\hline
\end{tabular}

Fig.4 (a) show the diffuse reflection spectra of these powder samples, it is obvious that the reflection rate decreased gradually with an increasing content of $\mathrm{Ga}^{3+}$, which has the same trend as the change of photoluminescence excitation spectra. All diffuse reflection curves can be divided to four part corresponding to the absorption of matrix and ${ }^{4} \mathrm{~A}_{2} \rightarrow{ }^{4} \mathrm{~T}_{1},{ }^{4} \mathrm{~A}_{2} \rightarrow{ }^{2} \mathrm{~T}_{2},{ }^{4} \mathrm{~A}_{2} \rightarrow{ }^{4} \mathrm{~T}_{2}$ transitions of $\mathrm{Mn}^{4+}$, respectively. It is consistent with the Gaussian fitting of PLE spectrum. The diffuse reflection spectra can be translated into UV-vis absorption spectra, and get the band gap energies further through the following equation ${ }^{32,33}$ :

$$
(\alpha h v)^{n}=A\left(h v-E_{g}\right)
$$


where $\alpha$ and $A$ are the absorption coefficient and proportional constant, $h v$ and $E_{g}$ refer to the photon energy and the band gap, respectively. Two values of $n$ are 2 and 1/2 means direct and indirect transition materials, respectively. The band gap energy of this series sample exhibits an upward and then a downward trend that increase from $5.25 \mathrm{eV}$ to $5.44 \mathrm{eV}$ then drop down to $5.21 \mathrm{eV}$, as shown in Fig.4 (b).
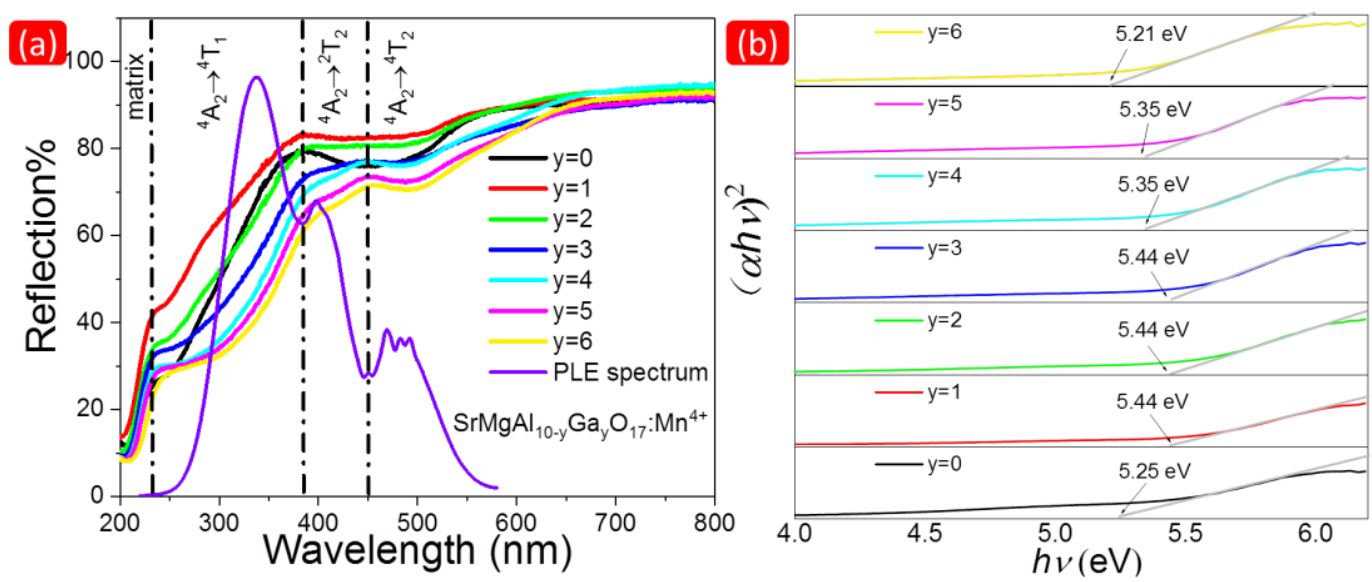

Fig.4 (a) The diffuse reflection spectra of $\mathrm{SrMgAl}_{10-\mathrm{y}} \mathrm{Ga}_{\mathrm{y}} \mathrm{O}_{17}: 1.0 \% \mathrm{Mn}^{4+}$ phosphors and one PLE spectrum of $\mathrm{SrMgAl}_{7} \mathrm{Ga}_{3} \mathrm{O}_{17}: 1.0 \% \mathrm{Mn}^{4+}$ sample; (b) corresponding band gap energy fitting.
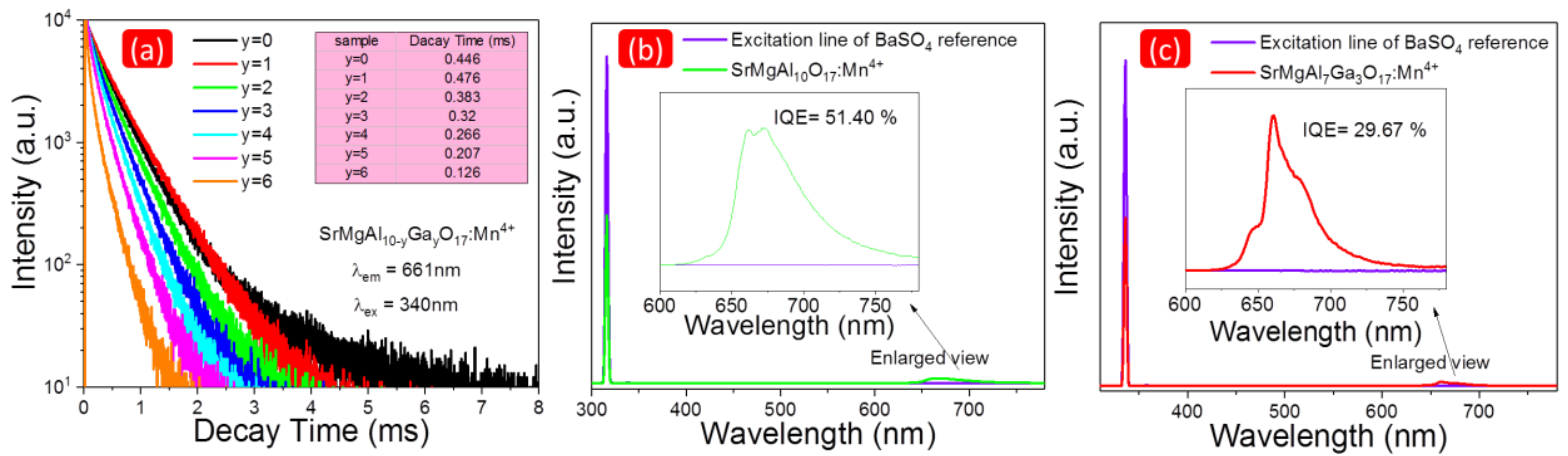

Fig.5 (a) The lifetime decay curves of $\mathrm{SrMgAl}_{10-\mathrm{y}} \mathrm{Ga}_{\mathrm{y}} \mathrm{O}_{17}: \mathrm{Mn}^{4+}$ phosphors monitored at $661 \mathrm{~nm}$; the measurement of quantum efficiency of (b) $\mathrm{SrMgAl}_{10} \mathrm{O}_{17}: \mathrm{Mn}^{4+}$ and (c) $\mathrm{SrMgAl}_{7} \mathrm{Ga}_{3} \mathrm{O}_{17}: \mathrm{Mn}^{4+}$, the insets are the enlarged pattern range from $600 \mathrm{~nm}$ to 780 nm.

In order to investigate the luminescence kinetics of $\mathrm{SrMgAl}_{10-\mathrm{y}} \mathrm{Ga}_{\mathrm{y}} \mathrm{O}_{17}: \mathrm{Mn}^{4+}$ phosphor, the lifetime of these samples were measured and display in Fig.5 (a). All of 
these curves fitting well with the double-exponential decay model, its expression is shown below ${ }^{34}$ :

$$
I(t)=I_{0}+C_{1} \exp \left(-t / \tau_{1}\right)+C_{2} \exp \left(-t / \tau_{2}\right)
$$

And the average life time can be further calculated as ${ }^{35}$ :

$$
t=\frac{C_{1} \tau_{1}^{2}+C_{2} \tau_{2}^{2}}{C_{1} \tau_{1}+C_{2} \tau_{2}}
$$

where $I$ and $I_{0}$ stand for the photoluminescence intensity at time $\mathrm{t}$ and time $0, C_{1}$ and $C_{2}$ refer to pre-exponential factors, $\tau_{1}$ and $\tau_{2}$ are the lifetime components, respectively. The lifetime of $\mathrm{SrMgAl}_{10-\mathrm{y}} \mathrm{Ga}_{\mathrm{y}} \mathrm{O}_{17}: \mathrm{Mn}^{4+}$ was calculated to be $0.446,0.476,0.383$, $0.320,0.266,0.207$ and $0.126 \mathrm{~ms}$ when the $\mathrm{Ga}^{3+}$ doping from 0 to $60 \%$. The double-exponential decay model indicates that $\mathrm{Mn}^{4+}$ should have two luminescence centers in $\mathrm{SrMgAl}_{10-\mathrm{y}} \mathrm{Ga}_{\mathrm{y}} \mathrm{O}_{17}$ matrix, which is consistent with the emission spectrum.

Quantum efficiency is an important parameter to evaluate luminescence property of phosphors, the experimental QE of $\mathrm{SrMgAl}_{10} \mathrm{O}_{17}: \mathrm{Mn}^{4+}$ and $\mathrm{SrMgAl}_{7} \mathrm{Ga}_{3} \mathrm{O}_{17}: \mathrm{Mn}^{4+}$ samples are shown in Fig.5 (b) and (c), which can be calculated via the following formula ${ }^{36,37}$ :

$$
\eta=\frac{\int L_{S}}{\int E_{R}-\int E_{S}}
$$

herein, $\eta$ is internal quantum efficiency, $L_{S}$ stands for the emission spectra of the sample, $E_{S}$ and $E_{R}$ are the reflection of excitation light with and without sample, respectively. The IQE of $\mathrm{SrMgAl}_{10} \mathrm{O}_{17}: \mathrm{Mn}^{4+}$ and $\mathrm{SrMgAl}_{7} \mathrm{Ga}_{3} \mathrm{O}_{17}: \mathrm{Mn}^{4+}$ are determined to be $51.40 \%$ and $29.67 \%$. It is interesting that $\mathrm{SrMgAl}_{7} \mathrm{Ga}_{3} \mathrm{O}_{17}: \mathrm{Mn}^{4+}$ with lower quantum efficiency exhibit stronger luminescence emission than $\mathrm{SrMgAl}_{10} \mathrm{O}_{17}: \mathrm{Mn}^{4+}$ sample, indicating $\mathrm{SrMgAl}_{7} \mathrm{Ga}_{3} \mathrm{O}_{17}: \mathrm{Mn}^{4+}$ has more potential for 
luminescence with further optimizing process.
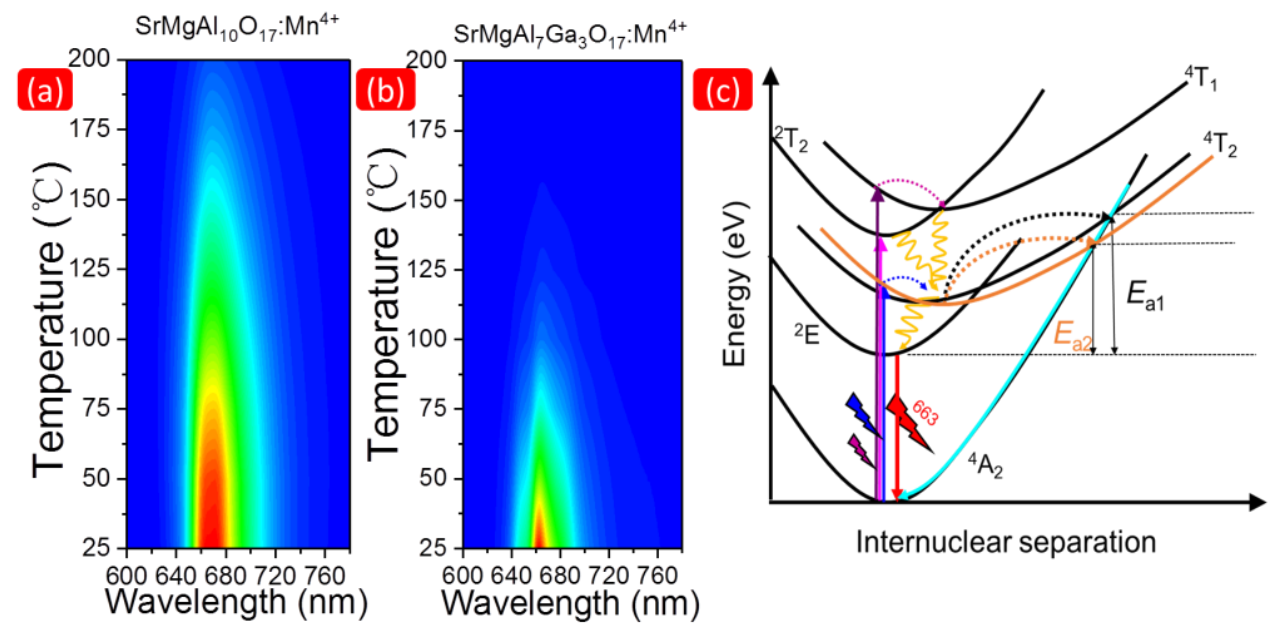

Fig.6 The temperature-dependence luminescence spectrum of (b) $\mathrm{SrMgAl}_{10} \mathrm{O}_{17}: \mathrm{Mn}^{4+}$ and (c) $\mathrm{SrMgAl}_{7} \mathrm{Ga}_{3} \mathrm{O}_{17}: \mathrm{Mn}^{4+}$; (c) configurational coordinate diagram for $\mathrm{Mn}^{4+}$ ions in $\mathrm{SrMgAl}_{10-\mathrm{y}} \mathrm{Ga}_{\mathrm{y}} \mathrm{O}_{17}$ phosphor.

The thermal stability of phosphor is evaluated by the temperature-dependence luminescence spectra which shown in Fig.6 (a) and (b). The emission intensity decreases rapidly as the temperature increases in both the two samples, and decline trend is more serious in $\mathrm{SrMgAl}_{7} \mathrm{Ga}_{3} \mathrm{O}_{17}: \mathrm{Mn}^{4+}$ phosphor. This result showed that $\mathrm{Ga}^{3+}$ doping could have destroyed the stability of matrix structure to some extent and caused to lower activation energy. It further promotes the loss of energy with non-radiative processes and resulted in worse thermal stability. 


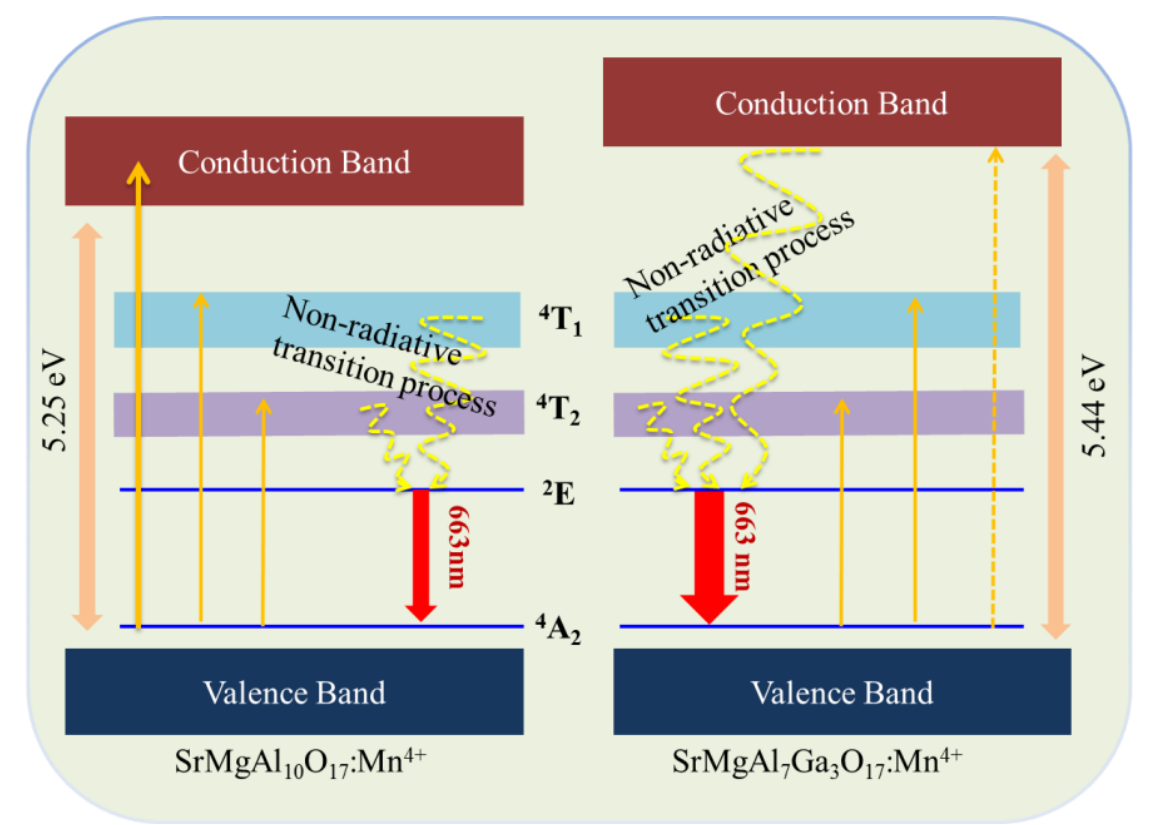

Fig.7 Mechanism diagram of luminescence in $\mathrm{SrMgAl}_{10-\mathrm{y}} \mathrm{Ga}_{\mathrm{y}} \mathrm{O}_{17}: \mathrm{Mn}^{4+}$ phosphor.

Fig. 7 shows the mechanism diagram in $\mathrm{SrMgAl}_{10-\mathrm{y}} \mathrm{Ga}_{\mathrm{y}} \mathrm{O}_{17}: \mathrm{Mn}^{4+}$ for clearly describing the energy transition process. There is only $\mathrm{Mn}^{4+}$ ion transition luminescence in the sample phosphors, $\mathrm{Mn}^{4+}$ is excited from ${ }^{4} \mathrm{~A}_{2}$ energy level to ${ }^{4} \mathrm{~T}_{1}$, ${ }^{4} \mathrm{~T}_{2}$ even conduction band, then drop to ${ }^{2} \mathrm{E}_{\mathrm{g}}$ level through non-radiative transition process, final relax to ${ }^{4} \mathrm{~A}_{2}$ level with bright red emission. The value of band-gap has an effect on energy transfer, excited electron often trapped by the conduction band and result in quenching directly with a narrow band-gap in $\operatorname{SrMgAl}_{10} \mathrm{O}_{17}: \mathrm{Mn}^{4+}$ phosphor. On the contrary, $\mathrm{SrMgAl}_{7} \mathrm{Ga}_{3} \mathrm{O}_{17}: \mathrm{Mn}^{4+}$ sample have wider band gap, so it is more difficult for excited ion jump into conduction band. This situation reduces the energy loss and more energy was using for photoluminescence, which is consistent with the experiment results. 


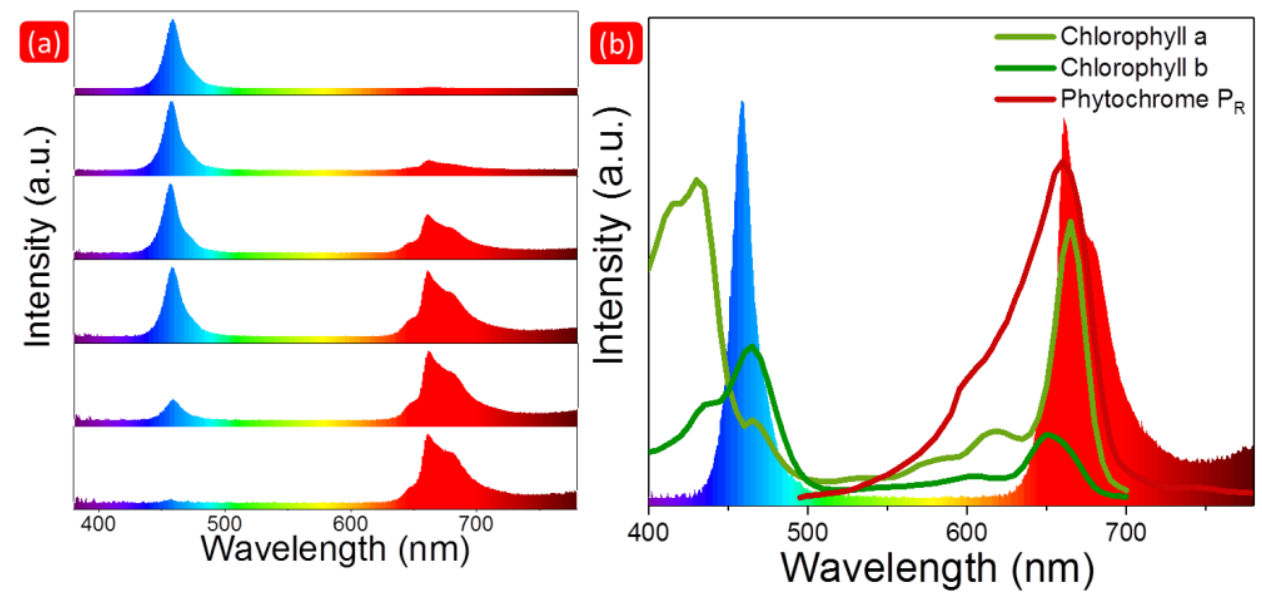

Fig.8 (a) Electro-luminescent spectra of the fabricated LEDs combined with $470 \mathrm{~nm}$ blue chip and different contents of $\mathrm{SrMgAl}_{7} \mathrm{Ga}_{3} \mathrm{O}_{17}: \mathrm{Mn}^{4+}$ sample; (c) the comprehensive comparison between EL spectra and the absorption curves of the plant pigments of Chlorophyll A, B and Phytochrome $\mathrm{P}_{\mathrm{R}}$.

In order to investigate the potential application of $\operatorname{SrMgAl}_{10-\mathrm{y}} \mathrm{Ga}_{\mathrm{y}} \mathrm{O}_{17}: \mathrm{Mn}^{4+}$ phosphor, LED devices were fabricated with $470 \mathrm{~nm}$ blue chips and different content of the as-obtained $\mathrm{SrMgAl}_{7} \mathrm{Ga}_{3} \mathrm{O}_{17}: \mathrm{Mn}^{4+}$ sample, their electro-luminescent spectra are shown in Fig.8. The red emission continue rising with the increasing content of phosphor, indicate the ratio of blue and red light can be easily adjust to adapt the needs of different plants growth. The electroluminescent spectrum of the fabricated red-emitting LED is mainly composed by blue band (420-500 nm) and red band $(650-750 \mathrm{~nm})$ with peak at $470 \mathrm{~nm}$ and $663 \mathrm{~nm}$, which can fit the absorption spectra of plant pigment including chlorophyl $\mathrm{A}$, chlorophyl $\mathrm{B}$ and phytochrome $\mathrm{P}_{\mathrm{R}}$ well, indicate the $\mathrm{SrMgAl}_{10-\mathrm{y}} \mathrm{Ga}_{\mathrm{y}} \mathrm{O}_{17}: \mathrm{Mn}^{4+}$ phosphors have potential to be a candidate in LED plant growth LED lights.

\section{Conclusion}


In this work, series of $\mathrm{Ga}^{3+}$-doped $\mathrm{SrMgAl}_{10} \mathrm{O}_{17}: \mathrm{Mn}^{4+}$ phosphors with enhanced luminescence properties were synthesized through high temperature approach. The $\mathrm{Ga}^{3+}$ dopants improve the luminescent intensity by $163 \%$ and cause the red shift in all photoluminescence excitation (PLE) and photoluminescence (PL) spectra and crystal field theory is using to explain the red shift phenomenon. All samples have a broad band of excitation spectra range from 220 to $580 \mathrm{~nm}$ indicate they can be excited by both near ultraviolet and blue chips. The phosphors exhibit bright red emission located at $663 \mathrm{~nm}$ corresponding to ${ }^{2} \mathrm{E}_{\mathrm{g}} \rightarrow{ }^{4} \mathrm{~A}_{2}$ transition of $\mathrm{Mn}^{4+}$. The $\mathrm{Ga}^{3+}$ doping increase the band gap of $\mathrm{SrMgAl}_{7} \mathrm{Ga}_{3} \mathrm{O}_{17}: \mathrm{Mn}^{4+}$ sample to reduce non-radiative transitions and improve the emission intensity while it has worse thermal stability for its low activation energy. Devices assembled with blue chip and the as-obtained $\mathrm{SrMgAl}_{7} \mathrm{Ga}_{3} \mathrm{O}_{17}: \mathrm{Mn}^{4+}$ phosphor emit bright blue and red light which match the plant absorption spectra well, indicating the $\mathrm{SrMgAl}_{10-\mathrm{y}} \mathrm{Ga}_{\mathrm{y}} \mathrm{O}_{17}: \mathrm{Mn}^{4+}$ phosphor have potential application on plant growth LED lighting.

\section{Conflicts of interest}

There are no conflicts to declare.

\section{Acknowledgements}

The authors would like to gratefully acknowledge funds from National Natural

Science Foundation of China (Grant No. 21706060, 51703061, 51974123), Natural

Sciences Foundation of Hunan Province, China (Grant No. 2017JJ3103), Scientific 
Research Foundation of Hunan Provincial Education Department (Grant No. 17B118),

Hunan Graduate Research and Innovation Project (Grant No. CX2018B396), Hunan

Provincial Engineering Technology Research Center for Optical Agriculture (Grant

No. 2018TP2003), The Scientific Research Fund of Hunan Provincial Education

Department (15K058) and Double first-class construction project of Hunan

Agricultural University (SYL201802002).

Reference (uncorrected, revise them before finalize)

1. Tomohiko Nakajima, T. T., Plant Habitat-Conscious White Light Emission of $\mathrm{Dy}^{3+}$ in Whitlockite-like Phosphates: Reduced Photosynthesis and Inhibition of Bloom Impediment. ACS Appl. Mater. Interfaces 2015, 7 (38), 21398-21407.

2. Sabzalian, M. R.; Heydarizadeh, P.; Zahedi, M.; Boroomand, A.; Agharokh, M.; Sahba, M. R.; Schoefs, B., High performance of vegetables, flowers, and medicinal plants in a red-blue LED incubator for indoor plant production. Agronomy for Sustainable Development 2014, 34 (4), 879-886.

3. L. Poulet, G. D. M., R.C. Morrowc, C.M. Bourget, R.M. Wheeler, C.A. Mitchell, Significant reduction in energy for plant-growth lighting in space using targeted LED lighting and spectral manipulation. Life Sci. Space Res. 2014, 2, 43-53.

4. J. Zhang, W. Z., X. Ji, W. Ma, Z. Qiu, L. Yu, C. Li, Z. Xia, Z. Wang, S. Lian, , Composition Screening in Blue-Emitting Li4Sr1+xCa0.97-x(SiO4)2:Ce(3+) Phosphors for High Quantum Efficiency and Thermally Stable Photoluminescence. ACS Appl Mater Interfaces 2017, 9 (36), 30746-30754.

5. Zhi Zhou, Y. Z., Mao Xia, Nan Zhou, Bingfu Lei, Jing Wang, Fangfang Wu, Tunable dual emission of $\mathrm{Ca}_{3} \mathrm{Al}_{4} \mathrm{ZnO}_{10}: \mathrm{Bi}^{3+}, \mathrm{Mn}^{4+}$ via energy transfer for indoor plant growth lighting. J. Mater. Chem. C 2018, 6, 8914-8922.

6. Cao, R.; Chen, T.; Ren, Y.; Chen, T.; Ao, H.; Li, W.; Zheng, G., Synthesis and photoluminescence properties of Ca2LaTaO6:Mn4+ phosphor for plant growth LEDs. Journal of Alloys and Compounds 2019, 780, 749-755.

7. Xianqing Piao, K.-i. M., Takashi Horikawa, Hiromasa Hanzawa, Yasuo Shimomura, Naoto Kijima, Preparation of $\mathrm{CaAlSiN}_{3}: \mathrm{Eu}^{2+}$ Phosphors by the Self-Propagating High-Temperature Synthesis and Their Luminescent Properties. Chem. Mater. 2007, 19, 4592-4599.

8. Jinwang Li, T. W., Hiroshi Wada,Tohru Setoyama, Masahiro Yoshimura, Low-Temperature Crystallization of Eu-Doped Red-Emitting CaAlSiN 3 from Alloy-Derived Ammonometallates. Chem. Mater. 2007, 19, 3592-3594.

9. Yi-Ting Tsai, C.-Y. C., Wuzong Zhou, Jyh-Fu Lee, Hwo-Shuenn Sheu, Ru-Shi Liu, Structural Ordering and Charge Variation Induced by Cation Substitution in $(\mathrm{Sr}, \mathrm{Ca}) \mathrm{AlSiN}_{3}$ :Eu Phosphor. Journal of the American Chemical Society 2015, 137 (28), 8936-9.

10. Y.Q. Li, J. E. J. v. S., J.W.H. van Krevel, G. Botty, A.C.A. Delsing, F.J. DiSalvo, G. de With, H.T. Hintzen, 
Luminescence properties of red-emitting $\mathrm{M}_{2} \mathrm{Si}_{5} \mathrm{~N}_{8}: \mathrm{Eu}^{2+}(\mathrm{M}=\mathrm{Ca}$, Sr, Ba) LED conversion phosphors. J. Alloys Compd. 2006, 417, 273-279.

11. Y.Q. Li, G. d. W., H.T. Hintzen, The effect of replacement of Sr by Ca on the structural and luminescence properties of the red-emitting $\mathrm{Sr}_{2} \mathrm{Si}_{5} \mathrm{~N}_{8}: \mathrm{Eu}^{2+}$ LED conversion phosphor. J. Solid State Chem. 2008, 181, 515-524.

12. Fang, M. H.; Hsu, C. S.; Su, C.; Liu, W.; Wang, Y. H.; Liu, R. S., Integrated Surface Modification to Enhance the Luminescence Properties of K2TiF6:Mn(4+) Phosphor and Its Application in White-Light-Emitting Diodes. ACS Appl Mater Interfaces 2018, 10 (35), 29233-29237.

13. Huang, L.; Liu, Y.; Yu, J.; Zhu, Y.; Pan, F.; Xuan, T.; Brik, M. G.; Wang, C.; Wang, J., Highly Stable K2SiF6:Mn4+@K2SiF6 Composite Phosphor with Narrow Red Emission for White LEDs. ACS Applied Materials \& Interfaces 2018, 10 (21), 18082-18092.

14. Zhou, Q.; Dolgov, L.; Srivastava, A. M.; Zhou, L.; Wang, Z.; Shi, J.; Dramićanin, M. D.; Brik, M. G.; $\mathrm{Wu}, \mathrm{M} ., \mathrm{Mn2}+$ and $\mathrm{Mn} 4+$ red phosphors: synthesis, luminescence and applications in WLEDs. A review. Journal of Materials Chemistry C 2018, 6 (11), 2652-2671.

15. Zhi Zhou, N. Z., Mao Xia, Yokoyama Meiso, H.T. (Bert) Hintzen, Research Progress and Application Prospect of Transition Metal $\mathrm{Mn}^{4+}$-Activated Luminescent Materials. J. Mater. Chem. C 2016, 4 (39), 9143-9161.

16. K. Sankarasubramanian, B. D., G. Annadurai, Liangling Sun, Yu-Jia Zeng, Xiaoyong Huang, Novel $\mathrm{SrLaAlO}_{4}: \mathrm{Mn}^{4+}$ deep-red emitting phosphors with excellent responsiveness to phytochrome PFR for plant cultivation LEDs: synthesis, photoluminescence properties, and thermal stability. RSC Adv. 2018, 8, 30223-30229.

17. Liangling Sun, B. D., Jia Liang, Bin Li, Shaoying Wang, Qi Sun, Heng Guo, Xiaoyong Huang, Thermally stable $\mathrm{La}_{2} \mathrm{LiSb}_{0} 6: \mathrm{Mn}^{4+}, \mathrm{Mg}^{2+}$ far-red emitting phosphors with over $90 \%$ internalquantum eficiency for plant growth LEDs. RSC Adv. 2018, 8, 31835-31842.

18. Jinmeng Xiang, J. C., Niumiao Zhang, Hebao Yao, Chongfeng Guo, Far red and near infrared double-wavelength emitting phosphor $\mathrm{Gd}_{2} \mathrm{ZnTiO}_{6}: \mathrm{Mn}^{4+}, \mathrm{Yb}^{3+}$ for plant cultivation LEDs. Dyes and Pigments 2018, 154, 257-262.

19. J. Chen, W. Z., N. Wang, Y. Meng, S. Yi, J. He, X. Zhang, , Energy transfer properties and temperature-dependent luminescence of Ca14Al10Zn6035: Dy3+, Mn4+ phosphors. J. Mater. Sci. 2016, 51 (9), 4201-4212.

20. Zhi Zhou, Y. L., Mao Xia, Yuan Zhong, Nan Zhou, H. T. (Bert) Hintzenc, Improved luminescence and energy-transfer properties of $\mathrm{Ca}_{14} \mathrm{Al}_{10} \mathrm{Zn}_{6} \mathrm{O}_{35}: \mathrm{Ti}^{4+}, \mathrm{Mn}^{4+}$ deep-red-emitting phosphors with high brightness for light-emitting diode (LED) plant-growth lighting. Dalton Trans. 2018, 47 (38), 13713-13721.

21. Yiyang Zhou, W. Z., Chongrui Lu, Zifeng Liao, Synthesis and luminescence properties of $\mathrm{Mn}^{4+}$ -dopant $\mathrm{Ca}_{14} \mathrm{Zn}_{6} \mathrm{Ga}_{10-x} \mathrm{Al}_{x} \mathrm{O}_{35}$ solid solution. Prog. Nat. Sci.: Mater. Int. 2018, 28 (3), 301-307.

22. Zhi Zhou, M. X., Yuan Zhong, Shujie Gai, Shengxiong Huang, Yun Tian, Xiangyang Lu, Nan Zhou, $\mathrm{Dy}^{3+} @ \mathrm{Mn}^{4+}$ co-doped $\mathrm{Ca}_{14} \mathrm{Ga}_{10-\mathrm{m}} \mathrm{Al}_{\mathrm{m}} \mathrm{Zn}_{6} \mathrm{O}_{35}$ far-red emitting phosphors with high brightness and improved luminescence and energy transfer properties for plant growth LED lights. J. Mater. Chem. $C$ 2017, 5, 8201-8210.

23. Qiao, J.; Zhang, Z.; Zhao, J.; Xia, Z., Tuning of the Compositions and Multiple Activator Sites toward Single-Phased White Emission in (Ca9- xSr x)MgK(PO4)7:Eu(2+) Phosphors for Solid-State Lighting. Inorganic chemistry 2019, 58 (8), 5006-5012.

24. X. Ji, J. Z., Y. Li, S. Liao, X. Zhang, Z. Yang, Z. Wang, Z. Qiu, W. Zhou, L. Yu and S. Lian, , Improving 
Quantum Efficiency and Thermal Stability in Blue-Emitting Ba2-xSrxSiO4:Ce3+ Phosphor via Solid Solution. Chem. Mater. 2018, 30 (15), 5137-5147.

25. Berdowski, P. A. M.; Blasse, G., Luminescence and energy transfer in a highly symmetrical system: Eu2Ti2O7. Journal of Solid State Chemistry 1986, 62 (3), 317-27.

26. Blasse, G., Energy Transfer in Oxidic Phosphors. Phys. Lett. A 1968, 28, 444-445.

27. Dexter, D. L., A Theory of Sensitized Luminescence in Solids. J. Chem. Phys. 1953, 21 (5), 836-850.

28. D. L. Dexter, J. H. S., Theory of Concentration Quenching in Inorganic Phosphors. J. Chem. Phys. 1954, 22 (6), 1063-1070.

29. Jiaqi Long, Y. W., Ran Ma, Chaoyang Ma, Xuanyi Yuan, Zicheng Wen, Miaomiao Du, Yongge Cao, Enhanced Luminescence Performances of Tunable $\mathrm{Lu}_{3-\mathrm{X}} \mathrm{Y}_{x} \mathrm{Al}_{5} \mathrm{O}_{12}: \mathrm{Mn}^{4+}$ Red Phosphor by lons of $\mathrm{Rn}^{+}\left(\mathrm{Li}^{+}\right.$, $\mathrm{Na}^{+}, \mathrm{Ca}^{2+}, \mathrm{Mg}^{2+}, \mathrm{Sr}^{2+}, \mathrm{Sc}^{3+}$ ). Inorg. Chem. 2017, 56 (6), 3269-3275.

30. Zhong, Y.; Gai, S.; Xia, M.; Gu, S.; Zhang, Y.; Wu, X.; Wang, J.; Zhou, N.; Zhou, Z., Enhancing quantum efficiency and tuning photoluminescence properties in far-red-emitting phosphor Ca14Ga10Zn6O35:Mn4+ based on chemical unit engineering. Chemical Engineering Journal 2019, 374, 381-391.

31. Jiang, C.; Zhang, X.; Wang, J.; Zhao, Q.; Wong, K.-L.; Peng, M., Synthesis and photoluminescence properties of a novel red phosphor SrLaGaO4

:Mn4+. Journal of the American Ceramic Society 2019, 102 (3), 1269-1276.

32. Xianbo Wu, L. L., Mao Xia, Shengxiong Huang, Yue Zhou, Wang Hu, Zhi Zhou and Nan Zhou, Enhance the luminescence properties of $\mathrm{Ca}_{14} \mathrm{Al}_{10} \mathrm{Zn}_{6} \mathrm{O}_{35}: \mathrm{Ti}^{4+}$ phosphor via cation vacancies engineering of $\mathrm{Ca}^{2+}$ and $\mathrm{Zn}^{2+}$. Ceramics International 2019, 45, 9977-9985.

33. Mao Xia, S. G., Cheng Zhou, Longhai Liu, Yuan Zhong, Yongli Zhang and Zhi Zhou Enhanced photoluminescence and energy transfer performance of Y3Al4GaO12:Mn4+,Dy3+ phosphors for plant growth LED lights. RSC Adv. 2019, 9, 9244-9252.

34. Hu, J.; Huang, T.; Zhang, Y.; Lu, B.; Ye, H.; Chen, B.; Xia, H.; Ji, C., Enhanced deep-red emission from $\mathrm{Mn}(4+) / \mathrm{Mg}(2+)$ co-doped CaGdAlO4 phosphors for plant cultivation. Dalton Trans 2019, 48 (7), 2455-2466.

35. Zhou, J.; Xia, Z., Luminescence color tuning of $\mathrm{Ce} 3+$, $\mathrm{Tb} 3+$ and Eu3+ codoped and tri-doped BaY2Si3010 phosphors via energy transfer. Journal of Materials Chemistry C 2015, 3 (29), 7552-7560.

36. Cao, R.; Sharafudeen, K. N.; Qiu, J., Enhanced luminescence in SrMgAl(x)O(17+/-delta):yMn4+ composite phosphors. Spectrochimica acta. Part A, Molecular and biomolecular spectroscopy 2014, $117,402-5$.

37. Liu, S.; Sun, P.; Liu, Y.; Zhou, T.; Li, S.; Xie, R. J.; Xu, X.; Dong, R.; Jiang, J.; Jiang, H., Warm White Light with a High Color-Rendering Index from a Single Gd3Al4GaO12:Ce(3+) Transparent Ceramic for High-Power LEDs and LDs. ACS Appl Mater Interfaces 2019, 11 (2), 2130-2139. 